\title{
Work at Bosscha Observatory
}

\author{
Moedji Raharto \\ Bosscha Observatiry, Lembang 40391, Java, Indonesia. e-mail: \\ moedji@sirius.as.itb.ac.id
}

\begin{abstract}
An overview is presented of work at Bosscha Observatory during the last ten years. Future developments are also discussed.
\end{abstract}

\section{Introduction}

Bosscha Observatory is one of the oldest observatories in Southeast Asia. It belongs to the Republic of Indonesia and operates under the Bandung Institute of Technology (ITB), Department of Education and Culture. The Observatory is located at a hill in Lembang with altitude $1310 \mathrm{~m}$ above sea level, geographical latitude $-6^{\circ} 49^{\prime}$ and longitude of $107^{\circ} 30^{\prime}$ East (or $7^{h} 10^{m}$ East); it is north of Bandung. The Observatory was founded in 1923, so it is 22 years older than the Republic of Indonesia. In the period 1923-1958 the Dutch astronomers contributed work at the Observatory and Indonesian astronomers have continued to develop the work since 1958. The population of the country is more than 200 millions and the area is about 2 million square degrees, spread over geographical longitude of $95^{\circ} \mathrm{E}$ to $140^{\circ} \mathrm{E}$ and latitude of $5^{\circ} \mathrm{N}$ to $10^{\circ} \mathrm{S}$; one third of the area is land and the rest is sea. For more detail about astronomy in Indonesia see Hidayat (1996) and van Albada-van Dien (1995).

ITB has three missions in higher education: to develop scientific and technical knowledge, to transmit such knowledge and to integrate it in society. Within the mission of ITB, Bosscha Observatory concentrates on contributing to the development of astronomy, but the Observatory also provides facilities for astronomical education, as well as facilities for education in science and technology.

An additional job for staff members at the Bosscha Observatory is to give popular lectures for visitors. "Astronomy for non-astronomers" may be an appropriate term. How we explain astronomy in popular ways depends on the educational level and background experiences of the visitors.

\section{Contribution to Astronomy}

The main instrumentation consists of 60-cm Zeiss double-refractors (focal lengths $10.78 \mathrm{~m}$ (in visual wavelengths) and $10.72 \mathrm{~m}$ (in photographic), a Schmidt telescope $(51 / 71 / 127 \mathrm{~cm})$, a GOTO Cassegrain $(45 \mathrm{~cm}$ aperture and $54 \mathrm{~m}$ focal 
length), the 37-cm Bamberg refractor with a focal length of $7 \mathrm{~m}$ and a Unitron $10.2-\mathrm{cm}$ refractor with a focal length of $1.5 \mathrm{~m}$.

The Zeiss double-refractors (visual and photographic) have been extensively used for observation of visual double stars. The visual telescope is dedicated to observing visual double stars with photographic plates. About 9000 plates of astrometric images of visual double stars with angular separations in the range of $2^{\prime \prime}-20^{\prime \prime}$ have been obtained through the visual telescope. The recent published data for visual double stars can be found in Jasinta et al. $(1994,1999)$, Jasinta and Hidayat (1999).

Observations of Mars have also been made with the visual telescope equipped with a planetary camera during the Mars opposition period in 1995 (Iwasaki et al., 1995).

In addition, the 37-cm Bamberg refractor has been used for photometric observations of variable stars (Malasan, 1996) and recently has been used for public education by showing lunar craters, planets and stars. After a new GOTO 45-cm Cassegrain telescope was installed in 1989, it was used for practically all the photoelectric photometry, see, for example, Okazaki et al., (1995). The 45-cm Cassegrain telescope is a computer-controlled telescope donated by the Japanese government donated under its cultural agreement. The telescope is equipped with photometer (Johnson UBV) and spectrograph.

The smaller Unitron refractor is suitable for lunar and solar observations. Imaging of eclipses of the Sun and Moon is also among its targets. The telescope is used for studying the proper motion of sunspots by some students (Soegiyono 2000, Herdiwijaya et al. 1997).

In 1958 , UNESCO donated a Schmidt telescope with a size of $51 / 71 / 127$ $\mathrm{cm}$ and field of view of $5^{\circ} \times 5^{\circ}$. The telescope is equipped with $6^{\circ}$-prism with a dispersion of $187 \mathrm{~nm} \mathrm{~mm}^{-1}$ at the A band $(\lambda 759.4 \mathrm{~nm})$. The survey telescope (plate scale $162^{\prime \prime} \mathrm{mm}^{-1}$ and $f$-ratio of about 2.5 ) is used for the M-star survey (Ichikawa et al., 1982). Observations of emission-line stars, of bright novae such as V382 Velorum, and astrometry of comets were also made with photographic plates (Hidayat et al., 1999 and Ikbal et al., 1995)

Several astronomical meetings have been held in Indonesia, for example IAU Colloquium No. 80 in 1983 on the occasion of the sixtieth anniversary of Bosscha Observatory (Hidayat et al. 1984), an IAU Symposium on Stellar Photometry and Spectral Classification in 1963 and IAU Symposium 143 on Wolf-Rayet Stars in 1991, the second IAU Regional Asia-Pacific Meeting on Astronomy in 1981 and IAU Schools for Young Astronomers in 1963 and 1983. Most recently, IAU Colloquium No. 148 on The Future Utilization of Schmidt Telescopes was held in Bandung in 1994 (Chapman et al. 1995).

\section{Some Notes on Maintenance and Development}

Staff from the department of astronomy in ITB contribute to the administrative work of the Observatory as well as doing some astronomical research with the Observatory's facilities. Economical and political crises began in Indonesia in 1997. The direct psychological impact of the crises made the younger generation think about survival and forget the development of science. It is not easy to find bright members of the younger generation willing to become astronomers. 
The uncontrolled prices and undervalued currency have made life harder. The currency is stabilizing now at about one-third of its previous value, so many things are about three times more expensive than they were before the crisis. Nobody thought about the serious impact of the economical and political crises on astronomy. Direct impacts will be on maintenance costs; the government cut our budget because most of the budget is now devoted to a great effort to help students, with scholarships, to continue their studies. The second direct impact comes from adjustment of the currency, which implies higher prices and higher operating costs in terms of the domestic currency.

It was good fortune for Bosscha Observatory that some supporting units, a PC computer network for Internet and a ST6B CCD camera were donated by a well-known company, Schlumberger, in 1999. The CCD camera is used to observe visual double stars with the Zeiss double refractor, as well as for stellar photometry. The continuation of support from LKBF for astronomical journals keeps the library up to date and the Internet connection runs well. We face a general problem that there is no budget for research and development; I hope that in the future a rich man or company will come to help.

Our experiences show that it is necessary to have a dedicated opticalelectronic engineer for astronomy as well as some budgetary provision for maintenance costs. At present, such human resources are less available, although there may be such people in other Departments (Physics, Engineering Physics, Electrical Engineering and Mechanical Engineering) in the Bandung Institute of Technology. Friendly relations with these Departments enable us to get help to identify or to solve instrumentation problems, but the time that the expert has avaialable may not be enough and weak commitment will be the result. Research and development, the backbone of the institution may stall or may not be well planned because of the lack of engineer and of an environment in which astronomers and engineers work together. We are not well prepared to maintain modern facilities like the GOTO telescope. After five years we face many problems with that telescope; some can be identified and solved by replacement with new material, but now the situation has become serious because the telescopecontrol system does not work. Photometric observations of dwarf novae with the GOTO telescope equipped with a CCD ST6B photometer, reported by Kunjaya (2000), and spectroscopy were in progress.

Work on astrometry, photometry, imaging and spectroscopy will be transferred from photographic plates to electronic detectors. It is difficult to set up a competitive program with a small telescope. Recently Le Poole (2000), a guest visitor from Leiden Observatory, proposed simultaneous spectroscopic work using the Bosscha Schmidt telescope with fiber optics.

Access to a new telescope is always an issue for Indonesian astronomers, as for other astronomers in Southeast Asia. Swarup (1981) and Swarup, Hidayat and Sukumar (1984) proposed collaboration on GERT (Giant Equatorial Radio Telescope). Politically, the proposal had been endorsed and supported by the Indonesian government, but now this project remains a plan; we have learned that without international collaboration, the Indonesian government will not be able to provide the whole budget needed.

Van der Hucht (1984) explored the possibilities of a plan for a new generation 2-m class telescope in Indonesia under the umbrella of INA (Indonesia- 
Netherlands Astrophysics). The light-pollution level at Bosscha Observatory is about 4 mag brighter than the dark sky (Malasan et al., 2000). A new site in Indonesia will be sought for the new telescope of 2-3 $\mathrm{m}$ size and joint efforts among ASEAN countries should be important for funding the project.

International cooperation and help for the young staff who continue their studies in astronomy and astrophysics are also important for the future of astronomy in Indonesia. We are optimistic that we shall survive for the next century, with different features.

\section{Exploring Public Awareness for an Active Role in the Development of Astronomy and Space Science}

The library is also one of the sources for research and education in astronomy in Indonesia. This library consists of the main astronomical journals and can be accessed by students in the Department of Astronomy. In addition, computer facilities, PCs with Internet connections, are used also for education. Basic observational science may be introduced through the telescopes. Students from various backgrounds, like architecture, cinema and art, often consult us about their thesis work concenred with space-science museums, observatories etc. In July 2000 we organized a month of training for 20 people from Indonesia, Brunei and Malaysia, to enhance astronomical knowledge of the Islamic calendar system. The Department of Religious Affairs in Indonesia sponsored that activity.

The informal Colloquium held at the Bosscha Observatory is a kind of melting-pot among scientists with different fields of interest. These activities are also an interactive process among scientists, as well as a process to educate new young scientists.

The potential synergy between space and ground-based astronomy will push frontiers of knowledge in astronomy and space science further. For example Raharto (1996) using optical data for M-type stars, obtained from a near-IR survey with the (relatively small) Bosscha Schmidt Telescope and from IRAS (InfraRed Astronomical Satellite) point sources, discovered optically luminous IR (InfraRed) sources which can be identified as M-type supergiants with large IR excesses, or AGB stars. Homogenous IR photometry of IR point sources with a high degree of completeness in almost all directions of the sky were obtained by IRAS in 1984. The data open the opportunity to study the overall structure of the Galaxy. The experience of the successful IRAS mission thus led to progress in space science and IR astronomy.

Many things remain to be explored from space and space exploration (for example, planetary or cometary exploration) needs more long-term investments and persistence of activity in research and education through several generations. It is necessary to enhance the impact of new knowledge and progress on the wider society. It is impportant to have local people always available to lecture in the local language and this warrants our continuing research activity. Human resources can be cultivated through higher education in astronomy, space science and related subjects. The total number of students in the Department of Astronomy is often directed by the availability of jobs in astronomy or space science, which is usually very limited. In Indonesia, graduates work in the satellite division or the computer-analysts division of the Aircraft Company 
IPTN, in Planetarium Jakarta, Aeronautic and Space Science (LAPAN), the Department of Astronomy in Indonesia or abroad etc. Some graduates work as bankers or journalists or in other areas. In Indonesia, the intake of students for Department of Astronomy is very small (for example, the intake of students for the undergraduate course in the Department of Astronomy in Bandung Institute of Technology is about 15 among the total intake at ITB of 1250 (compared to a total Indonesian population of 215 millions, spread over 2 million $\mathrm{km}^{2}$ in the equatorial region). The small number of students makes it difficult for the Department to be self-sustained; some additional funds are necessary to pay for the courses offered. The economical crisis, that began in 1997, made the situation worse. It became literally a matter of survival to fight critics of the budget for continuing astronomical research and education, confronted as we were by the basic needs of life, to increase of live salaries and to support education in other fields. A new concept of astronomical education is needed, that includes basic education in space science and recognizes that graduates can also fill the need for trained people with expertise in related areas of high technology. If that is accepted, then the solution to the problem of preparing the next generation of astronomers and space scientists could be found, through preparation of human resources for modern society. From the economic point of view only, it is hard to develop astronomy and space science in an underdeveloped country. The development of astronomy and space science in Indonesia will take longer due to these additional problems arising from the economical and political crises.

Another way to develop astronomy and space science may be through promoting the need for, and benefits, of space science for the future. It is frustrating to have to advertise astronomy and space science frequently but, in the long run, such a campaign may influence the opinion of politicians and decision-makers so that they make better provision for the development of space science. Unfortunately, the budget for high technology in Indonesia was recently cut, the reason given being that high technology spends too much money and the public does not get enough direct benefit from these activities. The politicians and decision-makers do not have enough time to discuss and to see even a little into the future. It is not easy to erase a wrong image of "luxurious" space science with little benefit to society. This situation is a kind of bottleneck in attempts to make a synergy between society, government, industry and education or research in space science.

Astronomy is closely related to space science; all astronomical objects are in outer space and observation of astronomical objects from space has opened a new horizon of astronomical knowledge. Nowadays ground-based and spacebased astronomy and astrophysics are very well developed in modern countries while, on the contrary, in underdeveloped countries they languish. This situation makes a big gap, in the activities of space exploration and dissemination of space science, between developing and developed countries. This gap gives the impression that astronomy and activities of space exploration are luxurious activities, and can only be a dream for people in underdeveloped countries. I suggest that we need to emphasize a policy that the worldwide progress of space science should also support existing bodies that are still struggling to survive and to develop in their difficult circumstances. Collaboration between countries in educational activities, exchanging knowledge and data, would be worthwhile and would overcome some of the difficulties of underdeveloped countries. 
The gap in knowledge between society and expert space-scientists becomes wider, for example, in the field of space-technology as more sophisticated and advanced technology, harder to understand, is used. The results of HST (Hubble Space Telescope), the Voyager and Apollo missions and other space missions are wonderful. How do we keep the public interest in them? How do we deepen the public interest so that people even begin to understand astrophysics? How do we give the public a sense that astronomy belongs to them? The public needs more information as the rate of progress of knowledge in astronomy and space-science accelerates. About 10,000 visitors come to Bosscha Observatory in Lembang every year and about 200,000 visit the Planetarium Jakarta. The visitors interact with astronomers through popular lectures on astronomy. These potential resources should be used to move the role of public from passive to active participants in the mainstream of development, or at least of transmission of new knowledge in astronomy and space-science to society.

That more than 10,000 people visit Bosscha Observatory's program of "Astronomy for Non-astronomers" every year provides another chance that our society will contribute directly to the Bosscha Observatory.

Acknowledgments. I would like to thank the IAU for providing a travel grant to attend the IAU GA 24 in Manchester. I appreciate very much the provision of hospitality during my stay in Manchester by the LOC of IAU GA 24. Finally I would like to thank Dr Alan Batten for valuable comments, suggestions and revision during editing the manuscript.

\section{References}

Chapman, J., Cannon, R., Harrizon, S. and Hidayat, B. (editors), 1995, The Future Utilization of Schmidt Telescopes, IAU Colloquium 148, ASP Conference Series No. 84.

Herdiwijaya, D., Makita, M., Anwar, B., 1997, PASJ vol. 49, 235-248

Hidayat, B., Kopal, Z. and Rahe, J. (editors), 1984, Double Stars, Physical Properties and Generic Relations Proceedings of IAU Colloquium No. 80 held at Lembang, Java.

Hidayat, B., 1995, in Chapman et al. (eds.) pp.

Hidayat, B., 1996, Journal of the Korean Astronomical Society 29, S455-S457

Hidayat, B., Ikbal, M., Wiramihardja, S.D., Raharto, M., 1999, Astronomissche Gesellschaft Tagung, Germany

Ichikawa, T., Hamajima, K., Ishida, K., Hidayat, B., and Raharto, M., 1982, PASJ 34, 231

Ikbal, M.A., Irfan, M., Raharto, M., Hidayat, B., 1995, Astronomische Nachrichten 317, 1581

Iwasaki, K., Sagar, R., Ghosh, K.K., Raharto, M. and Dirghantara, F., 1995, Lunar and Planetary Symposium 1-4

Jasinta, D.M.D., Soegiartini, E., 1994, Astron. Astrophy. Suppl. Ser. 107, 234-241

Jasinta, D.M.D., 1999, Proceedings of Fourth EAMA, Yunnan Obs., pp. 235-238 
Jasinta, D.M.D., Raharto M., Soegiartini, E., 1999, Astron. \& Astrophy. Suppl. Ser. 134,87

Jasinta, D.M.D., Hidayat, B., 1999, Astron. \& Astrophy. Ser. 136, 293-295

Kogure, T. and Hidayat, B. (editors), 1985, Galactic Structure and Variable Stars, Proc. Of the Three Year Cooperation in Astronomy between Indonesia and Japan 1979-1984

Kunjaya, C., 2000, Observation of Dwarf Nova (in preparation)

Le Poole, R., 2000, private communication

Malasan, H.L., 1996, Instrumentation and Research Programmes for Small Telescopes, IAU Symposium vol. 118, J.B. Hearnshaw and P. L. Cottrell eds. pp. 303-304, Reidel, Dordrecht.

Malasan, H.L., Senja, M.A., Hidayat, B. and Raharto, M., 2000, Preserving the Astronomical Sky, IAU Symposium 196, R. J. Cohen and W. T. Sullivan eds., pp. 1-4, ASP Publications.

Okazaki, A., Mahasenaputra and Hidayat, B., 1995, Southern Stars, vol. 36,65

Raharto, M., 1996, Study of Galactic Structure Based on M-Type Stars (RONPAKU - Thesis)

Soegiyono, 2000, (a thesis for Sarjana Science degree in Indonesian)

Swarup, G., 1984, Proceedings of Second Asian-Pacific Regional Meeting on Astronomy in 1981, 22-31

Swarup, G., Hidayat, B. and Sukumar, S., 1984, in Proceedings of IAU Colloquium no 80 Double Stars, Physical Properties and Generic Relations held at Lembang Java edited by B. Hidayat, Z. Kopal, and J. Rahe, 403-407

van Albada-van Dien, E., 1995, in The Future Utilization of Schmidt Telescopes, IAU Colloquium 148, 15-18.

van der Hucht, K.A., 1984, in Proceedings of IAU Colloquium no 80 Double Stars, Physical Properties and Generic Relations held at Lembang Java edited by B. Hidayat, Z. Kopal, and J. Rahe, 409-410 


\section{Discussion}

Orchiston asked if Indonesian astronomers had considered trying to establish collaborations with astronomers in other countries who could provide access to telescopes or data. Alternatively, had Indonesian astronomers thought of applying for service observing (which would not require their presence at the observatory) on, for example, the 3.0-m Anglo-Australian Telescope?

Rijsdijk suggested that, rather than training local people to use the Indonesian telescopes, those people sholud be sent abroad for training so that they could bring expertise back to Indonesia. With that added expertise, they could think of looking for new sites and telescopes. They could not expect foreign aid for sustaining their astronomy program to continue indefinitely.

Hearnshaw asked if there were any good dark sites in Indonesia, for telescopes in the $2 \mathrm{~m}$ to $3 \mathrm{~m}$ range. Raharto repeated that the sky brightness at Bosscha Observatory is about 4 magnitudes brighter than the darkest skies but he thought that there were several dark sites in Indonesia, for example in northern Sumatra, close to Toba Lake, or in the eastern part of the country, close to Timor Island. He thought that a telescope in the $2 \mathrm{~m}$ to $3 \mathrm{~m}$ range was very necessary for the future of astronomy in Southeast Asia.

Kitamura asked if there was sufficient support by technicians from other Departments. Raharto replied that there was no fixed arrangement for the Observatory to use technicians from other Departments and those who came were more committed to the institutions in which they worked. Observatory projects tended, therfore, to have low priority. 